\title{
The effectiveness of a coordinated preventive care approach for healthy ageing (UHCE) among older persons in five European cities: A pre-post controlled trial
} DOI:

10.1016/j.ijnurstu.2018.09.006

\section{Document Version \\ Accepted author manuscript}

Link to publication record in Manchester Research Explorer

Citation for published version (APA):

Franse, C. B., Van Grieken, A., Alhambra-borrás, T., Valía-cotanda, E., Van Staveren, R., Rentoumis, T., Markaki, A., Bilajac, L., Marchesi, V. V., Rukavina, T., Verma, A., Williams, G., Koppelaar, E., Martijn, R., Voorham, A. J. J., Mattace Raso, F., Garcés-ferrer, J., \& Raat, H. (2018). The effectiveness of a coordinated preventive care approach for healthy ageing (UHCE) among older persons in five European cities: A pre-post controlled trial. International Journal of Nursing Studies, 88, 153-162. https://doi.org/10.1016/j.ijnurstu.2018.09.006

\section{Published in:}

International Journal of Nursing Studies

\section{Citing this paper}

Please note that where the full-text provided on Manchester Research Explorer is the Author Accepted Manuscript or Proof version this may differ from the final Published version. If citing, it is advised that you check and use the publisher's definitive version.

\section{General rights}

Copyright and moral rights for the publications made accessible in the Research Explorer are retained by the authors and/or other copyright owners and it is a condition of accessing publications that users recognise and abide by the legal requirements associated with these rights.

\section{Takedown policy}

If you believe that this document breaches copyright please refer to the University of Manchester's Takedown Procedures [http://man.ac.uk/04Y6Bo] or contact uml.scholarlycommunications@manchester.ac.uk providing relevant details, so we can investigate your claim.

\section{OPEN ACCESS}


The effectiveness of a coordinated preventive care approach for healthy ageing (UHCE) among older persons in five European cities: a pre-post controlled trial.

Carmen B. Franse, $\mathrm{MSc}^{1}$; Amy van Grieken, $\mathrm{PhD}^{1}$; Tamara Alhambra-Borrás, $\mathrm{PhD}^{2}$; Elisa ValíaCotanda, $\mathrm{MSc}^{2}$; Rob van Staveren, $\mathrm{MSc}^{3}$; Tasos Rentoumis, $\mathrm{MSc}^{4}$; Athina Markaki, MSc ${ }^{4}$; Lovorka Bilajac, MSE, MPh, PhD ${ }^{5,6}$, Vanja Vasiljev Marchesi, MSE, PhD ${ }^{5,7}$; Tomislav Rukavina, MD, PhD ${ }^{5,6}$; Arpana Verma, $\mathrm{MD}, \mathrm{PhD}^{8}$; Greg Williams, $\mathrm{MSc}^{8}$; Elin Koppelaar, $\mathrm{PhD}^{9}$; Rens Martijn, $\mathrm{MSc}^{9}$; Antonius J.J. Voorham, $\mathrm{PhD}^{9}$; Francesco Mattace Raso, MD, PhD ${ }^{10}$; Jorge Garcés-Ferrer, PhD²; Hein Raat, MD, $\mathrm{PhD}^{1 *}$

Affiliations:

1-Erasmus University Medical Center, department of Public Health, Rotterdam, The Netherlands

2- Polibienestar Research Institute, University of Valencia, Valencia, Spain

3- Zorg Op Noord, Capelle aan den IJssel, The Netherlands

4- Alliance for integrated care, Athens, Greece

5-Faculty of Medicine University of Rijeka, Department of Social Medicine and Epidemiology, Rijeka, Croatia

6-Teaching institute of Public Health Primorsko-goranska County, Branch Office Opatija, Rijeka, Croatia

7-Faculty of Health Studies, University of Rijeka, Department of Public Health, Rijeka, Croatia 8- Manchester Urban Collaboration on Health, Centre for Epidemiology, Division of Population Health, Health Services Research and Primary Care, Manchester Academic Health Science Centre, The University of Manchester, Manchester, United Kingdom

9- Rotterdam University of Applied Sciences, Research Centre Innovation in Care, Rotterdam, The Netherlands

10-Erasmus University Medical Center, Section of geriatric medicine, department of Internal Medicine, Rotterdam, The Netherlands

* Corresponding author address: Hein Raat, Erasmus University Medical Center, department of Public Health, Wytemaweg 80, 3015 CN, Rotterdam, The Netherlands. E-mail:

h.raat@erasmusmc.nl

Funding: This work was supported by the European Union, CHAFEA, third health programme, grant number 20131201.

Running title: Effect of coordinated preventive care for healthy ageing

Impact statement: We certify that this work is novel. This study showed that a general template for preventive integrated care aimed at healthy ageing can successfully be implemented in various European settings.

Number Tables: 4 
42 Background: Older persons often have multiple health and social problems and need a variety

43 of health services. A coordinated preventive approach that integrates the provision of health

44 and social care services could promote healthy ageing. Such an approach can be organised

45 differently, depending on the availability and organizational structures in the local context.

46 Therefore, it is important to evaluate the effectiveness of a coordinated preventive care

47 approach in various European settings.

48 Objectives: This study explored the effects of a coordinated preventive health and social care

49 approach on the lifestyle, health and quality of life of community-dwelling older persons in five

50 European cities.

51 Design: International multi-center pre-post controlled trial.

52 Setting: Community settings in cities in the United Kingdom, Greece, Croatia, the Netherlands

53 and Spain.

54 Participants: 1844 community-dwelling older persons (mean age=79.5; SD=5.6).

55 Methods: The Urban Health Centres Europe (UHCE) approach consisted of a preventive

56 multidimensional health assessment and, if a person was at-risk, coordinated care-pathways

57 targeted at fall risk, appropriate medication use, loneliness and frailty. Intervention and control

58 sites were chosen based on their location in distinct neighbourhoods in the participating cities.

59 Persons in the catchment area of the intervention sites 'the intervention group' received the

60 UHCE approach and persons in catchment areas of the control sites 'the control group' received

61 care as usual. A questionnaire and two measurements were taken at baseline and at one-year 
62 follow-up to assess healthy lifestyle, fall risk, appropriate medication use, loneliness level,

63 frailty, level of independence, health-related quality of life and care use. To evaluate

64 differences in outcomes between intervention group and control group for the total study

65 population, for those who received follow-up care-pathways and for each city separately

66 (multilevel) logistic and linear regression analyses were used.

67 Results: Persons in the intervention group had less recurrent falls $(\mathrm{OR}=0.65,95 \% \mathrm{Cl}=0.48$;

$680.88)$ and lower frailty $(B=-0.43,95 \% \mathrm{Cl}=-0.65--0.22)$ at follow-up compared with persons in

69 the control group. Physical health-related quality of life and mental well-being was better

$70 \quad(B=0.95 ; 95 \% \mathrm{Cl}=0.14-1.76 ;$ and $\mathrm{B}=1.50 ; 95 \% \mathrm{Cl}=0.15-2.84$ respectively $)$. The effects of the

71 UHCE approach were stronger in the subgroup of persons (53.6\%) enrolled in care-pathways.

72 Conclusions: Our study found promising but minor effects for the use of a coordinated

73 preventive health and social care approach for the promotion of healthy ageing of older

74 persons. Future studies should further evaluate effects of coordinated preventive health and

75 social care aimed at healthy ageing.

76

77 Trial registration: ISRCTN registry number is ISRCTN52788952. Date of registration is

$78 \quad 13 / 03 / 2017$

79 Keywords: Europe, Frailty, Coordinated care, Multidisciplinary, Older persons, Prevention, pre80 post controlled trial, Primary care

81 


\section{What is already known:}

\section{9}

- As the population of older persons is growing, the number of older persons with social and health problems will also increase.

- A coordinated preventive health and social care approach with a multidimensional health assessment and multidisciplinary coordinated follow-up care was developed to answer the needs of older persons.

- The evidence of coordinated preventive care interventions in improving the health and quality of life of older persons is mixed.

\section{What this paper adds:}

- This study found small positive effects in tackling recurrent falls and frailty and promoting physical health-related quality of life and mental well-being among older persons involved who received the intervention.

- The effects of the UHCE approach were generally stronger in the subgroup of persons enrolled in care-pathways.

- A general template for coordinated preventive health and social care aimed at healthy ageing could potentially be successfully implemented in various European settings, although more research is needed to confirm our findings. 
101 It is estimated that by 2040 , Europeans over 65 years old will account for $27 \%$ of the 102 population, compared with $19 \%$ in $2015(1)$. This will be associated with a sharp increase in 103 demand for care. Promotion of healthy ageing is therefore a priority of European policy(2).

104 Older persons often have multiple health and social problems and need a variety of health 105 services $(3,4)$. However, care in Europe is characterised by a curative and monodisciplinary approach focussed on one illness or disease $(5,6)$. In addition, a focus on prevention and health

107 promotion could increase healthy life years and reduce the burden on health care resources(6).

108 As a result of this, the demand is growing for a preventive approach in which both health and 109 social care services are provided(6, 7).

110 A typical coordinated preventive care approach for older persons includes a multidimensional

111 assessment of health and social risks and multidisciplinary coordinated follow-up care(8-11). In

112 many European countries, general practitioners (GPs) are the gatekeepers to specialised care

113 and have a central role in community care(12). A nurse practitioner or physician assistant could

114 alleviate the burden of the GP and act as care coordinator. Evidence for preventive

115 interventions with multidisciplinary coordinated follow-up care is mixed and more research is

116 needed(13-15). Most of these studies have been conducted in Northwest European or

117 American settings, studies in Southern and Eastern European settings are lacking(16-19).

118 Aspects such as accessibility of primary care, availability of prevention and treatment services 119 and continuity of care vary considerably between European countries(6, 20). A striking example 120 is the difference between European countries in the importance and accessibility of GPs in 
121 community care(12). This has an impact on the role a GP could play and the organization of

122 care. Therefore, it is important to evaluate the effectiveness of coordinated preventive care

123 approaches in various European settings. Coordinated preventive health and social care can be

124 organised in many ways depending on the availability and organizational structures in the local

125 context.

126 Objective

127 The Urban Health Centres Europe (UHCE) approach was developed to promote healthy ageing

128 of older persons. The UHCE approach included a preventive multidimensional assessment of

129 health risks and, if indicated, coordinated follow-up health and social care. The UHCE approach

130 was specifically targeted at fall risk, appropriate medication use, loneliness and frailty. This

131 study evaluates the UHCE approach, which we hypothesized had a positive effect on lifestyle,

132 fall risk, appropriate medication use, loneliness, frailty, level of independence, health-related

133 quality of life and care use among community-dwelling older persons. 
137 Study design and setting

138 The effect evaluation of the UHCE approach was conducted in primary care and community

139 settings in five European cities (Greater Manchester, United Kingdom; Pallini, Greece; Rijeka,

140 Croatia; Rotterdam, the Netherlands; and Valencia, Spain) between May 2015 and June 2017. In

141 Manchester, Rijeka, Rotterdam and Valencia a specific pre-post controlled design was applied

142 (21). Randomization was not desirable for these cities that worked with existing GP practices as

143 it was not feasible for GPs to give 'usual care' and care according to UHCE at the same time. In

144 these cities, intervention and control sites (GP practices or primary health centres; PHC) were

145 chosen based on their location in distinct neighbourhoods in the participating cities. Older

146 persons in the catchment area of an intervention site receive an invitation by their physician to

147 join the study in the area where the UHCE approach is applied. Older persons in the catchment

148 area of a control site receive an invitation by their physician to join the study in the area where

149 'usual care' is applied (Table 1). In Pallini, participants from municipality registers were first

150 randomised by the use of a random numbers table into the intervention group and the control

151 group (Table 1). Participants were afterwards invited to participate in the study by a health

152 team of the municipality employed for this study. Ethical committee procedures have been

153 followed in all cities and approval has been provided. Written informed consent was obtained

154 from all participants. The study was registered as ISRCTN52788952. 
157 In each city, the initial target population consisted of persons living independently, aged 75 158 years or older, who were, according to their physician, able to participate in the study for at 159 least 6 months. Persons were not eligible to participate if they were not able to comprehend 160 the information provided in the local language or if they were not able to cognitively evaluate 161 the risks and benefits of participation and were not expected to be able to make an informed 162 decision regarding participation in the study, according to their physician. In two cities; Pallini 163 and Valencia, the age of the target population was lowered to 70 years or older due to 164 difficulties encountered during the inclusion. Persons were invited to participate in the study by 165 their health care provider (Table 1).

166 Intervention

167 In the intervention group, persons received care according to the UHCE approach. We used the 168 CREDICI II criteria for complex interventions as a reporting guideline(22), see Supplementary

169 text S1. The development of the UHCE approach followed an intervention mapping

170 approach(23). A general template for the UHCE approach was developed by systematically

171 reviewing the literature to identify evidence based interventions and validated assessment

172 instruments for fall risk, polypharmacy, loneliness and frailty (see www.uhce.eu). Additionally,

173 focus groups and interviews with main stakeholders (older persons, health and social care

174 professionals, caregivers and policy makers) were held to identify their needs and preferences

175 regarding healthy and active ageing. This led to the decision to address loneliness as a separate

176 health problem, in addition to frailty, fall risk and polypharmacy(24) as well as any medical

177 problems which were identified during the assessment that did not belong to the previously 
178 mentioned categories. We furthermore decided to apply an integral conceptual model of

179 frailty, which includes physical as well as social and psychological components and is geared

180 towards a multidisciplinary approach(25).

181 The general template of the UHCE approach consisted of three stages. In the first stage of the

182 UHCE approach, the older person received a health assessment of fall risk, polypharmacy,

183 loneliness and frailty in order to identify whether the person had an indication of a need for a

184 follow-up care-pathway. A short standardized assessment form was developed for all cities,

185 which consisted of validated instruments. For assessment of fall risk, a validated protocol

186 developed by the Dutch safety research institute was applied[15]. Assessment of polypharmacy

187 followed the common definition of using of five or more different medicines[16], in addition

188 difficulty in taking medications as prescribed was assessed[17]. Assessment of loneliness made

189 use of the social subscale of the Tilburg Frailty Indicator[18] and if loneliness was indicated

190 further assessment with the Jong-Gierveld loneliness scale[19]. The assessment of frailty

191 followed the Tilburg Frailty indicator for indication of frailty[18]. In the second stage of the

192 UHCE approach, shared-decision making took place; the results of the assessments (the

193 indications for care-pathways) were discussed with the older person, a person in charge of care

194 coordination and a physician. Staff encouraged the older person to involve an informal

195 caregiver in the shared-decision making process. Shared-decision making was included in order

196 to develop a care plan which was adapted to the preferences of the older person, which was

197 thought to promote involvement in care-pathways. In the third stage, as a result of the shared

198 decision-making process, a decision on a care plan was made and each participant was referred

199 to care-pathways. The care-pathways aimed to promote healthy ageing among the older 
persons by reducing fall risk, inappropriate medication use, loneliness and frailty. Specific interventions were recommended: 1) fall prevention actions; recommended evidence-based interventions were home-based exercise programmes, group exercise programmes and multifactorial assessment and intervention programmes, 2) actions addressing polypharmacy

204 (adherence and/or appropriate prescribing actions); recommended evidence-based interventions focused on self-monitoring programmes to improve adherence and/or multifaceted pharmaceutical care for appropriate prescribing, 3) actions addressing loneliness; recommended evidence-based interventions were social activities and/or support within a group format, and 4) frailty/medical action; recommended evidence-based interventions 209 included group exercise programmes and multidisciplinary care. Additionally in this care210 pathway, other medical care which did not fall under care-pathways 1-3 could be given when

211 the healthcare provider deemed this necessary. The care coordinator was asked to monitor the 212 progress of each individual care plan under the supervision of a physician. Follow-up visits could 213 be scheduled if needed. For this purpose, a uniform logbook was developed for all cities which 214 was kept for each older person who received the UHCE approach. In this logbook the care 215 coordinator recorded the outcomes and involvement of the older person and health staff in the 216 three stages (assessment, shared-decision and care-pathways) of the UHCE approach. The 217 results of this logbook, along with the evaluation of other process indicators, were part of the 218 evaluation of process components of the UHCE approach, following the Steckler and Linnan 219 framework(26). This evaluation has previously been described in more detail(24).

220 The general template of the UHCE approach was then adapted to the national standards and 221 context of each of the five participating cities. Specific information for each city; on the place 
222 and staff involved in the assessment, staff who acted as care coordinator, type of care and

223 health staff involved in the care-pathways, is reported in Table 1. Initially, the UHCE project

224 aimed to make use of or improve existing care available in the communities. However, in Pallini,

225 Rijeka and Valencia, the availability of existing care was limited or the referral to existing care

226 proved to be difficult. In these cases new care provisions were developed. No additional

227 monetary incentives were provided to health staff involved in existing care. In the settings

228 where new care was developed, staff was hired on a voluntary bases or compensated. No

229 monetary incentives were provided to participants. For some of the interventions participants

230 could borrow materials needed for the intervention (e.g. tablets). Persons in the control group

231 received their usual care. Participants in the control group had access to existing care services

232 delivered in the care-pathways, but not to newly developed services. No coordinated

233 preventive referral to existing care services nor coordinated preventive monitoring of health

234 was in place. In all cities except for Pallini, GPs were the first point of contact and had a

235 gatekeeper function towards existing care services. In Pallini, GPs were scarce and specialist

236 care was directly accessible upon appointment. 
Table 1. Study design, procedures and interventions of all cities in UHCE

\begin{tabular}{|c|c|c|c|c|c|}
\hline & Manchester, UK & Pallini, Greece & Rijeka, Croatia & Rotterdam, NL & Valencia, Spain \\
\hline $\begin{array}{l}\text { Source study } \\
\text { population }\end{array}$ & GP list & $\begin{array}{l}\text { Municipality/senior } \\
\text { centres registers }\end{array}$ & GP list & GP list & GP list \\
\hline $\begin{array}{l}\text { Method } \\
\text { invitation }\end{array}$ & Letter from GP & $\begin{array}{l}\text { Phone calls } \\
\text { municipality team }\end{array}$ & $\begin{array}{l}\text { In person by } \\
\text { community nurse }\end{array}$ & Letter from GP & $\begin{array}{l}\text { In person by nurse } \\
\text { or GP }\end{array}$ \\
\hline Age inclusion & $\geq 75$ years & $\geq 70$ years & $\geq 75$ years & $\geq 75$ years & $\geq 70$ years \\
\hline $\begin{array}{l}\text { Intervention } \\
\text { and control } \\
\text { group }\end{array}$ & $\begin{array}{l}\text { IG: GP practices in } \\
\text { Tameside and } \\
\text { Glossop districts. CG: } \\
\text { GP practices in South } \\
\text { Manchester }\end{array}$ & $\begin{array}{l}\text { Individual } \\
\text { randomization of } \\
\text { participants from } \\
\text { Pallini Municipality/ } \\
\text { senior centres }\end{array}$ & $\begin{array}{l}\text { IG: GP practices in } \\
\text { Western Rijeka. CG: } \\
\text { GP practices in } \\
\text { Eastern Rijeka }\end{array}$ & $\begin{array}{l}\text { IG: PHC in Ommoord } \\
\text { neighbourhood. CG: } \\
\text { PHCs in Oosterflank } \\
\text { and Zevenkamp } \\
\text { neighbourhoods }\end{array}$ & $\begin{array}{l}\text { IG: PHC in Nou } \\
\text { Moles } \\
\text { neighbourhood. CG: } \\
\text { PHC in El Botanic } \\
\text { neighbourhood }\end{array}$ \\
\hline Assessment & $\begin{array}{l}\text { At home by trained } \\
\text { assistant }\end{array}$ & $\begin{array}{l}\text { At senior/health } \\
\text { centre by HP }\end{array}$ & $\begin{array}{l}\text { At home by } \\
\text { community nurse }\end{array}$ & $\begin{array}{l}\text { At home by trained } \\
\text { assistant }\end{array}$ & $\begin{array}{l}\text { At home by trained } \\
\text { assistant }\end{array}$ \\
\hline $\begin{array}{l}\text { Care } \\
\text { coordinator }\end{array}$ & $\begin{array}{l}\text { Trained assistant } \\
\text { supervised by GP }\end{array}$ & HP or social worker & Community nurse & $\begin{array}{l}\text { Geriatric nurse } \\
\text { practitioner }\end{array}$ & $\begin{array}{l}\text { Trained assistant } \\
\text { supervised by GP }\end{array}$ \\
\hline $\begin{array}{l}\text { Type of care in } \\
\text { care-pathways }\end{array}$ & $\begin{array}{l}\text { Multiple per } \\
\text { pathway; e.g. home } \\
\text { adjustment by OT, } \\
\text { walking group by } \\
\text { volunteers (falls); } \\
\text { medication review by } \\
\text { GP (polypharmacy); } \\
\text { buddying services by } \\
\text { volunteers } \\
\text { (loneliness); further } \\
\text { care by GP (frailty). }\end{array}$ & $\begin{array}{l}\text { Group based } \\
\text { endurance and } \\
\text { balance training by PE } \\
\text { (falls); self-managed } \\
\text { medication adherence } \\
\text { App (polypharmacy); } \\
\text { support groups by } \\
\text { psychologist } \\
\text { (loneliness); further } \\
\text { care by physician } \\
\text { (frailty). }\end{array}$ & $\begin{array}{l}\text { Group based } \\
\text { balance and } \\
\text { strength training by } \\
\text { PT (falls and frailty); } \\
\text { self-managed } \\
\text { medication } \\
\text { adherence App } \\
\text { (polypharmacy); } \\
\text { social group } \\
\text { activities } \\
\text { (loneliness). }\end{array}$ & $\begin{array}{l}\text { Multiple per } \\
\text { pathway; e.g. } \\
\text { physiotherapy by PT } \\
\text { (falls); medication } \\
\text { review by pharmacist } \\
\text { (polypharmacy); } \\
\text { social activities } \\
\text { (loneliness); further } \\
\text { care by GP (frailty). }\end{array}$ & $\begin{array}{l}\text { Group based } \\
\text { balance and } \\
\text { strength training by } \\
\text { PT (falls and frailty), } \\
\text { medication review } \\
\text { according to } \\
\text { national protocol by } \\
\text { GP (polypharmacy), } \\
\text { social support group } \\
\text { led by social worker } \\
\text { (loneliness). }\end{array}$ \\
\hline $\begin{array}{l}\text { Care existing or } \\
\text { newly } \\
\text { developed }\end{array}$ & $\begin{array}{l}\text { All existing; offered } \\
\text { by local charity } \\
\text { organization and } \\
\text { according to practice } \\
\text { GP }\end{array}$ & All newly developed & $\begin{array}{l}\text { Falls, frailty and } \\
\text { polypharmacy } \\
\text { newly developed. } \\
\text { Loneliness existing } \\
\text { services }\end{array}$ & $\begin{array}{l}\text { All existing, medical } \\
\text { care according to } \\
\text { practice GP and } \\
\text { social care by local } \\
\text { organizations }\end{array}$ & $\begin{array}{l}\text { Falls, frailty and } \\
\text { loneliness newly } \\
\text { developed. } \\
\text { Polypharmacy } \\
\text { existing protocol }\end{array}$ \\
\hline
\end{tabular}

Abbreviations: $\mathrm{CG}=$ control group; $\mathrm{GP}=\mathrm{General}$ practitioner; $\mathrm{HP}=$ health professional; $\mathrm{IG}=$ intervention group; NL=The Netherlands;

$\mathrm{OT}=$ occupational therapist; $\mathrm{PE}=$ physical educator; $\mathrm{PHC}=$ primary care center; $\mathrm{PT}=$ physical therapist; UK=United Kingdom. 
Because the UHCE approach acted upon general health outcomes reported in the literature (16-

19) as well as health outcomes specific to care-pathways (depending on the care-pathway

persons were involved in), we explored the effect of the UHCE approach on various primary outcomes(24). We hypothesized that the UHCE approach would have positive effects on both general outcome measures of healthy lifestyle, level of independence and quality of life as well

244 as specific outcome measures to each care-pathway: fall risk, appropriate medication use,

245 loneliness and frailty. Data was collected at baseline and after 12 months by using a self-report

246 questionnaire and two physical measurements. The instruments and items for which no

247 validated translation was available were translated forward and backward. Forward- and back-

248 translations were discussed by the study team and translation was adapted when needed. In

249 each city, the questionnaire and assessment was piloted in at least five older persons.

250 Misinterpretation of questions were identified and minor changes were made. Measures used

251 are described below. Details of measurement of these measures are described in the

252 Supplementary Text S2.

253 General health outcome measures

254 Healthy lifestyle was measured with one item on physical activity, two items on smoking, and

255 three items of The Alcohol Use Disorders Identification Test (AUDIT-C)(27). Frailty was

256 measured with the 15-item Tilburg Frailty indicator (TFI); scores range from 0-15 with higher

257 scores indicating higher levels of frailty $(25,28)$. Physical frailty was additionally measured with

258 the SHARE-Frailty instrument $(29,30)$. Malnutrition, a component of physical frailty, was

259 measured with the validated Short Nutritional Assessment Questionnaire 65+ (SNAQ-65+)(31). 
260 Level of independence was measured with the 18-item Groningen activity restriction scale

261 (GARS); scores range from 18-72 with higher scores indicating lower levels of

262 independence(32). Severely limited function was measured with the one-item Global Activity

263 Limitation Index $(\operatorname{GALI})(33,34)$. Health-related quality of life was measured with the 12 -item

264 short-form (SF-12v2), which consists of physical and mental component summary (PCS/MCS)

265 scores $(35,36)$, and the full 5-item mental well-being scale of the SF-36(37). Scores for SF-12v2

266 and SF36 range from 0-100 with higher scores indicating higher levels of quality of life or well-

267 being.

268 Specific health outcomes care-pathways

269 Fall risk was measured by an item on any falls and an item on recurrent falls in the previous

270 year, an item on fear of falling, and fear of falling while performing several daily activities as

271 measured by the 7-item Falls Efficacy Scale International (FES-I) short version; scores range

272 from 7-28 with higher scores indicating higher levels of fear of falling (38). Appropriate

273 medication use was measured with 10 items of the Medication risk questionnaire (MRQ-10);

274 scores range from 0-10 with higher scores indicating lower levels of appropriate medication use

275 (39). Loneliness was measured with the 6-item version of the Jong Gierveld loneliness scale(40);

276 scores range from 6-18 with higher scores indicating higher levels of loneliness.

277 Care use

278 As secondary outcome measures, use of health and social care was measured in the

279 questionnaire. Four items measured, within the past 12 months: the number of visits to a

280 medical doctor, the number of days admitted to a hospital, the hours per week receiving help in 
281 household work due to health problems and the hours per week receiving help in caring for

282 oneself.

283 Socio-demographic factors

284 Age (in years), gender, living situation (alone/not alone) and education level were assessed in

285 the baseline questionnaire. Education level was measured by asking the highest level of

286 education completed and categorised according to the 2011 International Standard

287 Classification of Education (ISCED) into 'lower' (ISCED 0-2) and 'higher' (ISCED 3-8)(41).

289 Analysis

290 Participant socio-demographic characteristics and health outcomes were evaluated at baseline

291 between the intervention and control group in the total study population and in each city

292 separately by means of chi-square tests for categorical variables and one-way ANOVA for

293 continuous variables.

294 Main effects at follow-up were evaluated for the total study population, as per "intention to 295 treat", using a multilevel modelling approach. Clustering effects at city-level were taken into 296 account. Multilevel linear regression analyses were conducted for continuous outcome 297 variables with group (intervention or control) as independent variable. Multilevel logistic 298 regression was performed for dichotomous outcome variables. We corrected effect estimates

299 of multilevel analyses for covariates, based on literature (42); age, sex, living situation, 300 education level and the baseline status of the outcome variable. Subgroup "per-protocol" 301 analyses were done for persons with an indication for specific care-pathways. We compared 
persons in the control group who had an indication with persons in the intervention group who had an indication and enrolled in a care-pathway. Persons who received other types of medical care or did not have an indication but received care, were analysed in a separate 'frailty/medical care-pathway'. We compared persons in the frailty/medical care-pathway with all persons in the control group. We assessed interactions between intervention condition and city, gender, age and education level in the association between intervention condition and all outcomes(24). We applied Bonferroni correction for testing interactions(43) $(P=0.05 / 45=0.001)$. We found significant interaction for 'city', and performed linear and logistic regression analyses per city separately with the same variables as in the main analyses. We considered a P-value of 0.05 or lower to be statistically significant for all other analyses. Multilevel logistic regression analyses and interaction testing were performed using R-3.3.2. All other analyses were performed using SPSS version 23.0 (IBM SPSS Statistics for Windows, Armonk, NY: IBM Corp). A power calculation has been previously described(24). The target sample size was 1,250 participants in both the intervention group and the control group(24). Accounting for a $20 \%$ loss to follow-up, we expected to receive complete data of 1,000 participants in both groups at follow up. We assumed an alpha of 0.05 and power of 0.80 and applied a correction factor to account for the cluster design by city, assuming an average cluster size of 200 older citizens $(2,000 / 10)$ and an intra-class correlation coefficient of 0.02 . On this basis, a treatment difference of 0.25 standard deviation (SD) for continues outcomes such as the SF12 could be detected at follow-up. 
322 RESULTS

323 Overall, 1,215 persons were included in the intervention group and 1,110 persons in the control 324 group at baseline (Figure 1). At the 12-month follow-up, 986 persons in the intervention group

325 (81.2\%) completed the questionnaire and 858 persons in the control group (77.3\%) completed

326 the questionnaire (Figure 1). Reasons for drop-out at follow-up were unwillingness to

327 participate, feeling too ill to participate, mortality and relocation. Persons who dropped out of

328 the intervention group after baseline were older $(P<0.001)$, lower educated $(P<0.001)$ and had a

329 lower level of independence (GARS, $\mathrm{P}<0.001$ ) than persons included in the intervention group

330 at follow-up. Persons who dropped out of the control group only had a lower level of

331 independence (GARS, $P=0.003$ ) than persons included in the control group at follow-up. Of the

332986 persons in the intervention group, information of 15 persons on enrolment in care-

333 pathways was missing or could not be linked to study data. Of those with information, 520

334 (53.6\%) enrolled in any care-pathway during the UHCE study, this differed by city (Figure 1).

335 At baseline, the average age of persons in this study was 79.5 years $(S D=5.6), 60.8 \%$ of the

336 sample consisted of women, $38.1 \%$ were living alone and $51.1 \%$ had a lower education level

337 (Table 2). The fear of falling score measured with the short FES-I and loss of independence

338 score were lower and mental health-related quality of life and mental well-being were higher

339 among persons in the intervention group compared to the control group $(P<0.05)$. All other

340 characteristics were similar between the groups at baseline. Characteristics by city are

341 presented in Table S1. 
Table 2: Socio-demographic, lifestyle and health characteristics by intervention and control group among persons in the UHCE study ( $\mathrm{N}=1844)$.

\begin{tabular}{lcccc}
\hline & Total & Control group & Intervention group & P value \\
& $\mathrm{N}=1844$ & $\mathrm{~N}=858$ & $\mathrm{~N}=986$ & $79.3(5.7)$ \\
\hline Age in years, mean (SD) & $79.5(5.6)$ & $79.7(5.5)$ & 0.188 \\
Female gender, N (\%) & $1122(60.8)$ & $527(61.4)$ & $595(60.3)$ & 0.636 \\
Living alone, N (\%) & $703(38.1)$ & $323(37.7)$ & $380(38.5)$ & 0.708 \\
Lower education, N (\%) & $935(51.1)$ & $429(50.6)$ & $506(51.5)$ & 0.705 \\
& & & & \\
Healthy lifestyle, N (\%) & $1265(69.1)$ & $569(67.3)$ & $696(70.7)$ & 0.109 \\
Fear of falling, N (\%) & $867(47.0)$ & $410(47.8)$ & $457(46.3)$ & 0.538 \\
Fall past year, N (\%) & $552(30.2)$ & $267(31.4)$ & $285(29.1)$ & 0.278 \\
Recurrent falls past year, N (\%) & $255(13.9)$ & $118(13.9)$ & $137(14.0)$ & 0.953 \\
Physical frailty (SHARE-FI) & $367(20.2)$ & $180(21.5)$ & $187(19.1)$ & 0.204 \\
Severely limited function (GALI), N (\%) & $319(17.4)$ & $158(18.5)$ & $161(16.4)$ & 0.222 \\
Malnutrition (SNAQ-65+), N (\%) & $273(15.4)$ & $112(13.8)$ & $161(16.7)$ & 0.093 \\
& & & & \\
Fear of falling (short FES-I), mean (SD) & $10.5(4.7)$ & $10.7(5.0)$ & $10.3(4.5)$ & 0.038 \\
Medication risk (MRQ-10), mean (SD) & $4.4(1.6)$ & $4.4(1.6)$ & $4.4(1.7)$ & 0.358 \\
Loneliness (short JG), mean (SD) & $0.6(0.7)$ & $0.6(0.7)$ & $0.6(0.7)$ & 0.165 \\
Frailty (TFI), mean (SD) & $5.1(3.2)$ & $5.2(3.2)$ & $5.1(3.1)$ & 0.632 \\
Loss independence (GARS), mean (SD) & $25.0(9.4)$ & $25.5(10.2)$ & $24.5(8.7)$ & 0.022 \\
HRQoL PCS (SF-12), mean (SD) & $42.1(12.0)$ & $41.8(12.1)$ & $42.3(11.9)$ & 0.469 \\
HRQoL MCS (SF-12), mean (SD) & $50.3(10.6)$ & $49.3(10.7)$ & $51.2(10.4)$ & $<0.001$ \\
Mental well-being (SF-36), mean (SD) & $74.2(20.4)$ & $73.0(20.9)$ & $75.2(20.0)$ & 0.022 \\
\hline
\end{tabular}

Missing items: Age=1, Gender=0, Living situation=1, Education=13, Healthy lifestyle=14, Fear of falling=0;

Fall=16, Recurrent falls=16; SHARE-FI=26; GALI=9; SNAQ-65+=71; short FES-I=18, MRQ-10=22, short JG=23, $\mathrm{TFI}=8, \mathrm{GARS}=3, \mathrm{SF}-12=92$, SF-36=18. Lower education=ISCED 0-2; Healthy lifestyle= no smoking, no drinking and exercise>1 times a week. For short FES-I (range 7-28); MRQ-10 (range 0-10); short JG (range 6-18); TFI (range 0-15); GARS (range 18-72); higher scores mean worse health or more health risk. SF-12 and SF-36 scores range 0-100 and higher scores means a higher quality of life or better mental well-being. Abbreviations: FES-I= Falls Efficacy Scale International; GALI= Global Activity Limitation Index; GARS=Groningen activity restriction scale; ISCED=International Standard Classification of Education; JG=Jong-Gierveld; MRQ-10=Medication Risk Questionnaire 10; SF-12=short form 12; SF-36=short form 36; SHARE-FI= Survey of Health, Ageing and Retirement in Europe-Frailty Instrument; SNAQ-65+= Short Nutritional Assessment Questionnaire 65+; TFI=Tilburg Frailty Index.

343

344 At follow-up, persons in the intervention group had significantly less recurrent falls compared

345 to persons in the control group ( $10.5 \%$ vs. $14.8 \%$; OR= $0.65,95 \% \mathrm{Cl}=0.48-0.88$; Table 3 ). Frailty

346 was lower among persons in the intervention group compared to persons in the control group

347 (mean=4.9, $\mathrm{SD}=3.3$ vs mean=5.5, $\mathrm{SD}=3.4 ; \mathrm{B}=-0.43,95 \% \mathrm{Cl}=-0.65--0.22 ;$ Table 3). Physical

348 health-related quality of life was significantly better among persons in the intervention group 
349 compared to persons in the control group (mean=41.8, SD=12.1 vs $40.4, S D=11.5, B=0.95 ; 95 \%$

$350 \mathrm{Cl}=0.14-1.76 ;$ Table 3). Finally, mental well-being was significantly better among persons in the 351 intervention group compared to persons in the control group (mean=74.9, SD=20.5 vs

352 mean=71.8, SD=21.3, $\mathrm{B}=1.50 ; 95 \% \mathrm{Cl}=0.15-2.84$; Table 3). No other effects of the UHCE

353 approach on lifestyle, health or quality of life were found. Results by city are presented in Table 354 S2 and S3. In Rijeka, significant positive effects were found for nine outcomes. In Valencia, 355 significant positive effects were found for three outcomes and in Rotterdam for one outcome. 356 In Manchester, significant positive effects were found for one outcome and negative effects for 357 one outcome. No effects were found in Pallini. 
Table 3: Prevalence and mean of outcomes at follow-up and effects of the UHCE approach with the control group as reference $(\mathrm{N}=1844)$.

\begin{tabular}{lcccc}
\hline & $\begin{array}{c}\text { Control group } \\
\mathrm{N}=858\end{array}$ & $\begin{array}{c}\text { Intervention group } \\
\mathrm{N}=986\end{array}$ & $\begin{array}{c}\text { Adjusted effect } \\
\text { estimates }\end{array}$ & P value \\
\hline Healthy lifestyle & $\mathrm{N}(\%)$ & $\mathrm{N}(\%)$ & $\mathrm{OR}(95 \% \mathrm{Cl})^{\mathrm{a}}$ & \\
Fear of falling & $555(65.4)$ & $678(68.9)$ & $0.96(0.68 ; 1.34)$ & 0.790 \\
Fall past year & $441(51.6)$ & $472(48.1)$ & $0.86(0.68 ; 1.08)$ & 0.188 \\
Recurrent falls past year & $267(31.3)$ & $280(28.9)$ & $0.92(0.74 ; 1.14)$ & 0.441 \\
Physical frailty (SHARE-FI) & $126(14.8)$ & $102(10.5)$ & $0.65(0.48 ; 0.88)$ & 0.005 \\
Severely limited function (GALI) & $245(29.4)$ & $236(24.8)$ & $0.78(0.60 ; 1.02)$ & 0.065 \\
Malnutrition (SNAQ-65+) & $176(20.7)$ & $192(19.7)$ & $1.09(0.83 ; 1.43)$ & 0.539 \\
& $135(17.1)$ & $145(15.3)$ & $0.82(0.62 ; 1.09)$ & 0.181 \\
& & & & \\
Fear of falling (short FES-I) & Mean (SD) & Mean (SD) & $\mathrm{B}(95 \% \mathrm{Cl})^{\mathrm{b}}$ & \\
Medication risk (MRQ-10) & $11.5(5.4)$ & $10.8(5.2)$ & $-0.25(-0.60 ; 0.10)$ & 0.167 \\
Loneliness (short-JG) & $4.4(1.6)$ & $4.4(1.6)$ & $0.03(-0.09 ; 0.15)$ & 0.653 \\
Frailty (TFI) & $0.7(0.7)$ & $0.6(0.7)$ & $-0.10(-0.24 ; 0.03)$ & 0.128 \\
Loss independence (GARS) & $5.5(3.4)$ & $4.9(3.3)$ & $-0.43(-0.65 ;-0.22)$ & $<0.001$ \\
HRQoL PCS (SF-12) & $27.4(11.9)$ & $26.4(10.8)$ & $-0.11(-0.73 ; 0.52)$ & 0.742 \\
HRQoL MCS (SF-12) & $40.4(11.5)$ & $41.8(12.1)$ & $0.95(0.14 ; 1.76)$ & 0.022 \\
Mental well-being (SF-36) & $48.8(11.3)$ & $50.6(11.2)$ & $0.52(-0.32 ; 1.37)$ & 0.224 \\
\hline
\end{tabular}

a) Values are derived from random-intercept multilevel logistic regression models adjusted for clustering by city and adjusted for age, gender, education, living situation and baseline status of the outcome measure. b) Values are derived from random-intercept multilevel linear regression models adjusted for clustering by city and adjusted for age, gender, education, living situation and baseline status of the outcome measure. Healthy lifestyle= no smoking, no drinking and exercise>1 times a week. For short FES-I (range 7-28); MRQ-10 (range 0-10); short JG (range 6-18); TFI (range 0-15); GARS (range 18-72); higher scores mean worse health or more health risk. SF-12 and SF-36 scores range 0-100 and higher scores means a higher quality of life or better mental well-being. Abbreviations: B=Beta coefficient; FES-I= Falls Efficacy Scale International; JG=JongGierveld; MRQ-10=Medication Risk Questionnaire 10; OR=Odds ratio; SF-12=short form 12; SF-36=short form 36; SHARE-FI= Survey of Health, Ageing and Retirement in Europe-Frailty Instrument; SNAQ-65+= Short Nutritional Assessment Questionnaire 65+; TFI=Tilburg Frailty Index.

When comparing persons who enrolled in any type of care-pathway with all persons in the

control group (Table 4), adjusted significant effects were stronger compared to the whole

361 intervention group for recurrent falls $(\mathrm{OR}=0.58,95 \% \mathrm{Cl}=0.40-0.85)$, frailty $(\mathrm{B}=-0.44,95 \% \mathrm{Cl}=-$

$3620.71--0.17)$ and physical health-related quality of life $(B=1.22,95 \% \mathrm{Cl}=0.24-2.21)$. Additionally

363 there was a positive effect on loneliness $(B=-0.18,95 \% \mathrm{Cl}=-0.35--0.02)$. The positive effect on

364 mental well-being was no longer significant. 
were found on frailty and physical health-related quality of life (Table S4). For persons in the

371 For persons in the polypharmacy care-pathway no positive effects were found.

Table 4: Prevalence and mean of outcomes at follow-up and effects of the UHCE approach for persons enrolled in any care-pathway with the control group as reference ( $\mathrm{N}=1378)$.

\begin{tabular}{lcccc}
\hline & $\begin{array}{c}\text { Control group } \\
\mathrm{N}=858\end{array}$ & $\begin{array}{c}\text { Intervention group } \\
\mathrm{N}=520\end{array}$ & $\begin{array}{c}\text { Adjusted effect } \\
\text { estimates }\end{array}$ & P value \\
\hline Healthy lifestyle & $\mathrm{N}(\%)$ & $\mathrm{N}(\%)$ & $\mathrm{OR}(95 \% \mathrm{Cl})^{\mathrm{a}}$ & \\
Fear of falling & $555(65.4)$ & $334(64.5)$ & $1.04(0.67 ; 1.62)$ & 0.848 \\
Fall past year & $441(51.6)$ & $302(58.2)$ & $0.83(0.63 ; 1.11)$ & 0.215 \\
Recurrent falls past year & $267(31.3)$ & $142(27.6)$ & $0.82(0.63 ; 1.06)$ & 0.129 \\
Physical frailty (SHARE-FI) & $126(14.8)$ & $51(9.9)$ & $0.58(0.40 ; 0.85)$ & 0.005 \\
Severely limited function (GALI) & $245(29.4)$ & $154(31.0)$ & $0.87(0.64 ; 1.18)$ & 0.360 \\
Malnutrition (SNAQ-65+) & $176(20.7)$ & $126(24.6)$ & $1.19(0.86 ; 1.64)$ & 0.303 \\
& $135(17.1)$ & $103(20.6)$ & $1.05(0.76 ; 1.46)$ & 0.755 \\
& & & & \\
Fear of falling (short FES-I) & Mean (SD) & Mean (SD) & $\mathrm{B} \mathrm{(95 \%} \mathrm{Cl)}$ & \\
Medication risk (MRQ-10) & $11.5(5.4)$ & $12.3(5.7)$ & $-0.24(-0.68 ; 0.21)$ & 0.299 \\
Loneliness (short-JG) & $4.4(1.6)$ & $4.5(1.7)$ & $0.08(-0.07 ; 0.23)$ & 0.312 \\
Frailty (TFI) & $0.7(0.7)$ & $0.7(0.7)$ & $-0.18(-0.35 ;-0.02)$ & 0.033 \\
Loss independence (GARS) & $5.5(3.4)$ & $5.9(3.3)$ & $-0.44(-0.71 ;-0.17)$ & 0.001 \\
HRQoL PCS (SF-12) & $27.4(11.9)$ & $28.3(12.0)$ & $0.06(-0.75 ; 0.87)$ & 0.886 \\
HRQoL MCS (SF-12) & $40.4(11.5)$ & $40.3(11.8)$ & $1.22(0.24 ; 2.21)$ & 0.015 \\
Mental well-being (SF-36) & $48.8(11.3)$ & $46.7(11.8)$ & $-0.31(-1.39 ; 0.76)$ & 0.568 \\
\hline
\end{tabular}

a) Values are derived from random-intercept multilevel logistic regression models adjusted for clustering by city and adjusted for age, gender, education, living situation and baseline status of the outcome measure. b) Values are derived from random-intercept multilevel linear regression models adjusted for clustering by city and adjusted for age, gender, education, living situation and baseline status of the outcome measure. Healthy lifestyle= no smoking, no drinking and exercise $>1$ times a week. For short FES-I (range 7-28); MRQ-10 (range 0-10); short JG (range 6-18); TFI (range 0-15); GARS (range 18-72); higher scores mean worse health or more health risk. SF-12 and SF-36 scores range 0-100 and higher scores means a higher quality of life or better mental well-being. Abbreviations: B=Beta coefficient; FES-I= Falls Efficacy Scale International; JG=JongGierveld; MRQ-10=Medication Risk Questionnaire 10; OR=Odds ratio; SF-12=short form 12; SF-36=short form 
36; SHARE-FI= Survey of Health, Ageing and Retirement in Europe-Frailty Instrument; SNAQ-65+= Short Nutritional Assessment Questionnaire 65+; TFI=Tilburg Frailty Index.

372

373 Regarding care use, the number of hours per week needing household help due to health

374 problems was reduced among persons in the intervention group compared to persons in the

375 control group (Table S5). There were no effects on the use of doctor visits, hospital admissions

376 and help in self-care.

377 


\section{DISCUSSION}

379

380

381

382

383

384

\section{Principal findings}

Using a pre-post controlled design, we explored the effects of the UHCE approach on multiple outcomes of the lifestyle, health and quality of life among older persons in five European cities. The UHCE approach showed minor positive effects in tackling recurrent falls and frailty and promoting physical health-related quality of life and mental well-being compared to care as usual. Effects were stronger in the subgroup of persons who enrolled in care-pathways.

\section{Interpretation}

It is promising that we found positive effects of the UHCE approach on tackling recurrent falls and frailty and promoting physical health-related quality of life and mental well-being. However, the effect sizes of these outcomes were minor for the whole intervention group and minor or small for the subgroup of persons who enrolled in care-pathways. Furthermore, our study was exploratory in the sense that we measured effects on multiple outcomes which increases the chances of finding false positive results due to chance alone. Several systematic reviews report favourable effects of similar interventions on falls, functional decline, nursing home admissions and mortality $(16,18,19)$, but others do not $(17,44)$. Effects on quality of life are less studied and evidence is of low quality(17). A possible reason for the small effects found in our study is that only around half of the persons in the intervention group enrolled in carepathways. The dose in which older persons take-up complex care interventions is rarely studied and could impact on the effectiveness of interventions $(19,26)$. For professionals, parts of the intervention might be time consuming or difficult to apply $(42,45)$. For older persons, health and mobility problems can be barriers to engagement in interventions $(45,46)$. The effects of 
400 the UHCE approach on health and quality of life were stronger when evaluating the subsample

401 of persons enrolled in care-pathways. When analysing care-pathways separately, positive

402 effects on fall outcomes, frailty and quality of life were found in persons who followed the falls

403 prevention, frailty and/or loneliness care-pathways. As part of the falls prevention and frailty

404 care-pathways most persons received physical exercise programmes. There is ample evidence

405 on the benefits of physical exercise programmes for the prevention of falls and risk of falling in

406 older populations(47-49) and to a lesser extent frailty(50), mental health and quality of life(51,

407 52). The polypharmacy care-pathway did not decrease inappropriate medication use for

408 persons enrolled in this care-pathway. The MRQ-10 instrument used to measure inappropriate

409 medication use might have not been sensitive enough to detect a change.

410 To our knowledge this was the first coordinated preventive care study conducted in multiple

411 European settings. Most of the studies on coordinated preventive health and social care have

412 been conducted in the US, Canada or Northwest Europe(16-19). In these settings, care for older

413 persons was greatly improved during the 1980 s to 1990 s and care interventions after that time

414 might have been of little extra benefit(19). This could explain the low uptake of care in the

415 Northwest European cities Manchester and Rotterdam. In these cities, qualitative analyses of

416 logbooks revealed that many older persons reported that they did not enrol in a care-pathway

417 because they were already involved in other care. Most positive effects of the UHCE approach

418 were found in Rijeka, where all persons in the intervention group enrolled in a care-pathway.

419 Possible explanations for the high uptake of care in Rijeka were a high morale to engage in

420 activities among participants and regular monitoring of the care process by community nurses

421 who had a personal relationship with the participants and acted as care coordinator in this 
422 study. Establishment of a trusted relationship is important for improvement of uptake and

423 adherence to care interventions among older persons(46). This therefore could be a key

424 component of future studies. These studies could quantitatively explore to what extent the

425 bond between patient and care provider impacts on effectiveness.

426 In our study, not using additional inclusion criteria such as frailty or multi-morbidity might also

427 have impacted on enrolment in care-pathways as participants could have been too healthy to

428 need care. However, frail persons might in turn not be fit and willing enough to engage in

429 preventive care. Evidence on effective intervention components of coordinated care

430 interventions and target populations has been mixed $(16,19)$. In a meta-analysis, Beswick et al.

431 found reductions in nursing home admissions for populations with increased death rates and

432 no benefits for any specific type of intervention among multifactorial interventions(19).

433 Though, Stuck et al. found that only interventions with a multidimensional geriatric assessment,

434 regular follow-up visits and targeted at persons at lower risk for death were effective in

435 reducing functional decline(16). More research is needed to uncover the effective elements and

436 target groups of complex coordinated preventive care interventions for older persons. In order

437 to identify these elements, reporting of the development and evaluation of these complex

438 interventions should be streamlined(22, 53). It could also be possible that structured and

439 preventive monitoring and promotion of the health of older persons could result in stronger

440 health benefits within a longer time span, as our study only measured effects in one year.

$441 \quad$ Future studies should investigate the long-term effects of a coordinated preventive care

442 approach for older persons.

443 Strengths and Limitations 
444 The main strength of our study is that we implemented the UHCE approach in five diverse

445 European cities. This provides information on the effectiveness and generalisability of a

446 coordinated preventive care approach in various European settings. With the use of a uniform

447 questionnaire and measurements we were able to apply the same evaluation design in all cities

448 and there were few missing data. There were also some limitations. First, although we almost

449 reached our targeted sample size for the intervention group, we did not for the control group.

450 Especially in Pallini and Rotterdam there were difficulties including persons in the control group

451 despite attempts to boost participation. Selective inclusion cannot be excluded, although

452 differences between control group and intervention group at baseline were small. To account

453 for differences in sample size between cities, we used a multilevel modelling approach in

454 analyses. Persons lost to follow-up in the intervention group were older and had a lower level

455 of independence compared to persons in the intervention group included in the analyses.

456 Therefore, the UHCE approach might have reached a relatively healthy group of older persons.

457 Secondly, we applied a non-randomised design, which makes results subject to confounding

458 variables. However, differences between persons in the control and intervention group at

459 baseline were small. Third, whereas the UHCE project initially aimed to make use of existing

460 care provisions, this was not always possible in all settings. This may have impacted the

461 acceptability of the UHCE approach, especially in cases where health staff was newly employed,

462 who were unfamiliar to the older participants.

\section{Conclusions}

464 Our study found promising but minor effects for the use of a coordinated preventive health and 465 social care approach for the promotion of healthy ageing of older persons. Future studies 
466 should further evaluate the effects of coordinated preventive health and social care aimed at

467 healthy ageing in diverse European settings. The main challenge is participation in care of this

468 vulnerable older population. Therefore, effective strategies are needed to promote

469 engagement in care, tailored to the needs of older persons. More research is needed to

470 determine the specific effective components of coordinated preventive health and social care

471 that contribute to health improvements of older persons. 


\section{Acknowledgements}

473 We would like to thank all participating older persons and all organizations and professionals

474 involved in the UHCE project for their contributions to the UHCE study. We especially would like

475 to thank the following individuals for their contributions to this study: Filian Looman, Eline

476 Speijer and Petra de Vries.

\section{Author contributions}

$478 \mathrm{HR}, \mathrm{AJJV}$ and RVS designed initial study protocol and wrote the funding proposal. CF and HR

479 specified the initial study protocol with regards to the design, measurements, data

480 management and analysis plan. EV, TR, LB advised on the use of research methods. TA, EV, TR,

$481 \mathrm{LB}, \mathrm{RvS}, \mathrm{AV}, \mathrm{GW}$ coordinated the intervention in each city. CF did the analyses. CF drafted the

482 manuscript and AvG and HR supervised the writing process. All authors critically revised the

483 manuscript for important intellectual content. All authors approved the final manuscript.

484 Conflict of interest

485 The authors declare that they have no competing interests

486 Availability of data

487 The datasets used and/or analysed during the current study are available from the

488 corresponding author on reasonable request.

489 Consent for publication

$490 \quad$ Not applicable. 
492 This work was supported by the European Union, CHAFEA, third health programme, grant 493 number 20131201.

494 Ethical approval and consent to participate

495 Ethical committee procedures have been followed in all cities and institutions involved, and 496 approval has been provided. The names of the review board and the approval references are:

497 Manchester, United Kingdom: NRES Committee West Midlands - Coventry \& Warwickshire; 06498 03-2015; 15/WM/0080; NRES Committee South Central - Berkshire B; 29-20-2014; 14/SC/1349; 499 Pallini, Greece: The Ethics and Scientific board - Latriko Palaiou Falirou Hospital; 04/03/2015; 500 20150304-01; Rijeka, Croatia: The Ethical Committee - Faculty of Medicine University of Rijeka;

501 07-04-2014; 2170-24-01-14-02; Rotterdam, The Netherlands: Medische Ethische Toetsings 502 Commissie (METC) - Erasmus MC Rotterdam; 08/01/2015; MEC-2014-661; Valencia, Spain: 503 Comisión de Investigación - Consorcio Hospital General Universitario de Valencia. 29/01/2015;

504 CICHGUV-2015-01-29. Written consent is obtained from all participants. 
507 1. Eurostat. Population structure and ageing: European Union, 1995-2013; 2014 [05/01/2017].

508 Available from: http://ec.europa.eu/eurostat/statistics-

509 explained/index.php/Population structure and ageing.

$5102 . \quad$ European Innovation Partnership on Active and Healthy Ageing. Specific Action on innovation in

511 support of 'Personalized health management, starting with a Falls Prevention Initiative' Brussels:

512 European Commision; 2013. Available from:

513 https://ec.europa.eu/eip/ageing/sites/eipaha/files/library/51a44f911f647 a2 action plan.pdf. 3. Andrew MK, Mitnitski A, Kirkland SA, Rockwood K. The impact of social vulnerability on the survival of the fittest older adults. Age Ageing. 2012;41(2):161-5.

4. Mendes de Leon CF, Glass TA, Berkman LF. Social engagement and disability in a community population of older adults: the New Haven EPESE. Am J Epidemiol. 2003;157(7):633-42. PubMed PMID: 12672683.

5. Glasby J. The holy grail of health and social care integration. BMJ. 2017;356:j801. doi: 10.1136/bmj.j801. PubMed PMID: 28209566.

5216 Kringos DS, Boerma WGW, Hutchinson A, Saltman RB, European Observatory on Health S, 522 Policies. Building primary care in a changing Europe2015.

523 7. Nolte E, Knai C, McKee M, Organizacion Mundial de la S, European Obsrvatory on Health S, 524 Policies. Managing chronic conditions : experience in eight countries. Copenhagen: World Health Organization on behalf of the European Observatory on Health Systems and Policies; 2009.

8. $\quad$ Frich LM. Nursing interventions for patients with chronic conditions. J Adv Nurs. 2003;44(2):13753. Epub 2003/10/03. doi: 2779 [pii]. PubMed PMID: 14521681.

9. Markle-Reid M, Browne G, Weir R, Gafni A, Roberts J, Henderson SR. The effectiveness and efficiency of home-based nursing health promotion for older people: a review of the literature. Med Care Res Rev. 2006;63(5):531-69. Epub 2006/09/07. doi: 63/5/531 [pii]

10.1177/1077558706290941. PubMed PMID: 16954307.

10. Markle-Reid M, Browne G, Gafni A. Nurse-led health promotion interventions improve quality of life in frail older home care clients: Lessons learned from three randomized trials in Ontario, Canada. J Eval Clin Pract. 2013;19(1):118-31.

11. Liebel DV, Friedman B, Watson NM, Powers BA. Review of nurse home visiting interventions for community-dwelling older persons with existing disability. Med Care Res Rev. 2009;66(2):119-46. Epub 2008/12/31. doi: 1077558708328815 [pii]

538 10.1177/1077558708328815. PubMed PMID: 19114607.

539 12. Eurostat. Healthcare personnel statistics - physicians: European Commission; 2017 [cited 2017

540 17/11/2017]. Available from: http://ec.europa.eu/eurostat/statistics-

541 explained/index.php/Healthcare personnel statistics - physicians\#Further Eurostat information.

542 13. Cattan M, White M, Bond J, Learmouth A. Preventing social isolation and loneliness among older 543 people: a systematic review of health promotion interventions. Ageing Soc. 2005;25:41-67. doi: DOI 544 10.1017/Soi44686X04002594. PubMed PMID: ISI:000227072000004.

545 14. Hagan R, Manktelow R, Taylor BJ, Mallett J. Reducing loneliness amongst older people: a 546 systematic search and narrative review. Aging Ment Health. 2014;18(6):683-93. Epub 2014/01/21. doi: 547 10.1080/13607863.2013.875122. PubMed PMID: 24437736.

548 15. Dickens AP, Richards SH, Greaves CJ, Campbell JL. Interventions targeting social isolation in older 549 people: a systematic review. BMC Public Health. 2011;11:647. Epub 2011/08/17. doi: 1471-2458-11-647 550 [pii] 
10.1186/1471-2458-11-647. PubMed PMID: 21843337; PubMed Central PMCID: PMC3170621. 16. Stuck AE, Egger M, Hammer A, Minder CE, Beck JC. Home visits to prevent nursing home admission and functional decline in elderly people: systematic review and meta-regression analysis. JAMA. 2002;287(8):1022-8. Epub 2002/02/28. doi: jma10044 [pii]. PubMed PMID: 11866651.

17. Mayo-Wilson E, Grant S, Burton J, Parsons A, Underhill K, Montgomery P. Preventive home visits for mortality, morbidity, and institutionalization in older adults: a systematic review and meta-analysis. PLoS One. 2014;9(3):e89257. Epub 2014/03/14. doi: 10.1371/journal.pone.0089257

PONE-D-13-47215 [pii]. PubMed PMID: 24622676; PubMed Central PMCID: PMC3951196.

18. Huss A, Stuck AE, Rubenstein LZ, Egger M, Clough-Gorr KM. Multidimensional preventive home visit programs for community-dwelling older adults: a systematic review and meta-analysis of randomized controlled trials. J Gerontol A Biol Sci Med Sci. 2008;63(3):298-307. Epub 2008/04/01. doi: 63/3/298 [pii]. PubMed PMID: 18375879.

19. Beswick AD, Rees K, Dieppe P, Ayis S, Gooberman-Hill R, Horwood J, et al. Complex interventions to improve physical function and maintain independent living in elderly people: a systematic review and meta-analysis. Lancet. 2008;371(9614):725-35. Epub 2008/03/04. doi: S0140-6736(08)60342-6 [pii]

10.1016/S0140-6736(08)60342-6. PubMed PMID: 18313501; PubMed Central PMCID: PMC2262920.

20. World Health Organization. Primary health care : now more than ever2008.

21. Miller JN, Colditz GA, Mosteller F. How study design affects outcomes in comparisons of therapy. II: Surgical. Stat Med. 1989;8(4):455-66. PubMed PMID: 2727469.

22. Mohler R, Kopke S, Meyer G. Criteria for Reporting the Development and Evaluation of Complex Interventions in healthcare: revised guideline (CReDECI 2). Trials. 2015;16:204. doi: 10.1186/s13063015-0709-y. PubMed PMID: 25935741; PubMed Central PMCID: PMCPMC4461976.

23. Bartholomew LK, Parcel GS, Kok G. Intervention mapping: a process for developing theory- and evidence-based health education programs. Health Educ Behav. 1998;25(5):545-63. Epub 1998/10/13. PubMed PMID: 9768376.

24. Franse CB, Voorham AJJ, van Staveren R, Koppelaar E, Martijn R, Valia-Cotanda E, et al. Evaluation design of Urban Health Centres Europe (UHCE): preventive integrated health and social care for community-dwelling older persons in five European cities. BMC Geriatr. 2017;17(1):209. doi: 10.1186/s12877-017-0606-1. PubMed PMID: 28893178; PubMed Central PMCID: PMCPMC5594491. 25. Gobbens RJ, Luijkx KG, Wijnen-Sponselee MT, Schols JM. Towards an integral conceptual model of frailty. J Nutr Health Aging. 2010;14(3):175-81. PubMed PMID: 20191249.

26. Steckler ABLL. Process evaluation for public health interventions and research. San Francisco, Calif.: Jossey-Bass; 2002.

27. Bush K, Kivlahan DR, McDonell MB, Fihn SD, Bradley KA. The AUDIT alcohol consumption questions (AUDIT-C): an effective brief screening test for problem drinking. Ambulatory Care Quality Improvement Project (ACQUIP). Alcohol Use Disorders Identification Test. Arch Intern Med. 1998;158(16):1789-95. PubMed PMID: 9738608.

28. Gobbens RJ, van Assen MA, Luijkx KG, Wijnen-Sponselee MT, Schols JM. The Tilburg Frailty Indicator: psychometric properties. J Am Med Dir Assoc. 2010;11(5):344-55. doi: 10.1016/j.jamda.2009.11.003. PubMed PMID: 20511102.

29. Romero-Ortuno R, Walsh CD, Lawlor BA, Kenny RA. A frailty instrument for primary care: findings from the Survey of Health, Ageing and Retirement in Europe (SHARE). BMC Geriatr. 2010;10:57. Epub 2010/08/25. doi: 1471-2318-10-57 [pii]

10.1186/1471-2318-10-57. PubMed PMID: 20731877; PubMed Central PMCID: PMC2939541. 30. Romero-Ortuno R. The Frailty Instrument for primary care of the Survey of Health, Ageing and Retirement in Europe predicts mortality similarly to a frailty index based on comprehensive geriatric 
assessment. Geriatr Gerontol Int. 2013;13(2):497-504. Epub 2012/09/22. doi: 10.1111/j.14470594.2012.00948.x. PubMed PMID: 22994136; PubMed Central PMCID: PMC3530023.

31. Wijnhoven HA, Schilp J, van Bokhorst-de van der Schueren MA, de Vet HC, Kruizenga HM, Deeg DJ, et al. Development and validation of criteria for determining undernutrition in community-dwelling older men and women: The Short Nutritional Assessment Questionnaire 65+. Clinical Nutrition. 2012;31(3):351-8. PubMed PMID: 22119209.

32. Suurmeijer TP, Doeglas DM, Moum T, Briancon S, Krol B, Sanderman R, et al. The Groningen Activity Restriction Scale for measuring disability: its utility in international comparisons. Am J Public Health. 1994;84(8):1270-3. PubMed PMID: 8059884.

33. van Oyen $\mathrm{H}$, Van der Heyden J, Perenboom R, Jagger C. Monitoring population disability: evaluation of a new Global Activity Limitation Indicator (GALI). Soz Praventivmed. 2006;51(3):153-61. PubMed PMID: 17191540.

34. Berger N, Van Oyen H, Cambois E, Fouweather T, Jagger C, Nusselder W, et al. Assessing the validity of the Global Activity Limitation Indicator in fourteen European countries. BMC Med Res Methodol. 2015;15:1. doi: 10.1186/1471-2288-15-1. PubMed PMID: 25555466; PubMed Central PMCID: PMCPMC4298058.

35. Haywood KL, Garratt AM, Fitzpatrick R. Quality of life in older people: a structured review of generic self-assessed health instruments. Qual Life Res. 2005;14(7):1651-68. Epub 2005/08/27. PubMed PMID: 16119178.

36. Ware J, Jr., Kosinski M, Keller SD. A 12-Item Short-Form Health Survey: construction of scales and preliminary tests of reliability and validity. Med Care. 1996;34(3):220-33. Epub 1996/03/01. PubMed PMID: 8628042.

37. Ware JE, Jr., Sherbourne CD. The MOS 36-item short-form health survey (SF-36). I. Conceptual framework and item selection. Med Care. 1992;30(6):473-83. PubMed PMID: 1593914.

38. Yardley L, Beyer N, Hauer K, Kempen G, Piot-Ziegler C, Todd C. Development and initial validation of the Falls Efficacy Scale-International (FES-I). Age Ageing. 2005;34(6):614-9. PubMed PMID: 16267188.

39. Barenholtz Levy H. Self-administered medication-risk questionnaire in an elderly population. Annals of Pharmacotherapy. 2003;37(7-8):982-7. PubMed PMID: 12841804.

40. De Jong Gierveld J, Van Tilburg T. The De Jong Gierveld short scales for emotional and social loneliness: tested on data from 7 countries in the UN generations and gender surveys. Eur J Ageing. 2010;7(2):121-30. doi: 10.1007/s10433-010-0144-6. PubMed PMID: 20730083; PubMed Central PMCID: PMCPMC2921057.

41. Organisation for Economic C-o, Development. Classifying educational programmes : manual for ISCED-97 implementation in OECD countries. Paris: Organisation for Economic Co-operation and Development; 1999.

42. Metzelthin SF, van Rossum E, de Witte LP, Ambergen AW, Hobma SO, Sipers W, et al. Effectiveness of interdisciplinary primary care approach to reduce disability in community dwelling frail older people: cluster randomised controlled trial. BMJ. 2013;347:f5264. Epub 2013/09/12. PubMed PMID: 24022033; PubMed Central PMCID: PMC3769159.

43. McDonald JH, University of D. Handbook of biological statistics. Baltimore, Maryland: Sparky House Publishing; 2009.

44. Bouman A, van Rossum E, Nelemans P, Kempen GI, Knipschild P. Effects of intensive home visiting programs for older people with poor health status: a systematic review. BMC Health Serv Res. 2008;8:74. Epub 2008/04/05. doi: 1472-6963-8-74 [pii]

10.1186/1472-6963-8-74. PubMed PMID: 18387184; PubMed Central PMCID: PMC2364620. 
45. Metzelthin SF, Daniels R, van Rossum E, Cox K, Habets H, de Witte LP, et al. A nurse-led interdisciplinary primary care approach to prevent disability among community-dwelling frail older people: a large-scale process evaluation. Int J Nurs Stud. 2013;50(9):1184-96. Epub 2013/02/07. doi: S0020-7489(12)00458-0 [pii]

10.1016/j.ijnurstu.2012.12.016. PubMed PMID: 23384696.

46. Provencher V, Mortenson WB, Tanguay-Garneau L, Belanger K, Dagenais M. Challenges and strategies pertaining to recruitment and retention of frail elderly in research studies: a systematic review. Arch Gerontol Geriatr. 2014;59(1):18-24. doi: 10.1016/j.archger.2014.03.006. PubMed PMID: 24745811.

47. El-Khoury F, Cassou B, Charles MA, Dargent-Molina P. The effect of fall prevention exercise programmes on fall induced injuries in community dwelling older adults: systematic review and metaanalysis of randomised controlled trials. BMJ. 2013;347:f6234. Epub 2013/10/31. PubMed PMID: 24169944; PubMed Central PMCID: PMC3812467.

48. Gillespie LD, Robertson MC, Gillespie WJ, Lamb SE, Gates S, Cumming RG, et al. Interventions for preventing falls in older people living in the community. Cochrane Database Syst Rev.

2009(2):CD007146. Epub 2009/04/17. doi: 10.1002/14651858.CD007146.pub2. PubMed PMID: 19370674.

49. Howe TE, Rochester L, Neil F, Skelton DA, Ballinger C. Exercise for improving balance in older people. Cochrane Database Syst Rev. 2011(11):CD004963. Epub 2011/11/11. doi: 10.1002/14651858.CD004963.pub3. PubMed PMID: 22071817.

50. Theou O, Stathokostas L, Roland KP, Jakobi JM, Patterson C, Vandervoort AA, et al. The effectiveness of exercise interventions for the management of frailty: a systematic review. J Aging Res. 2011;2011:569194. Epub 2011/05/18. doi: 10.4061/2011/569194. PubMed PMID: 21584244; PubMed Central PMCID: PMC3092602.

51. Bridle C, Spanjers K, Patel S, Atherton NM, Lamb SE. Effect of exercise on depression severity in older people: systematic review and meta-analysis of randomised controlled trials. Br J Psychiatry. 2012;201(3):180-5.

52. Park SH, Han KS, Kang CB. Effects of exercise programs on depressive symptoms, quality of life, and self-esteem in older people: a systematic review of randomized controlled trials. Appl Nurs Res. 2014;27(4):219-26. doi: 10.1016/j.apnr.2014.01.004. PubMed PMID: 24602398.

53. Campbell M, Fitzpatrick R, Haines A, Kinmonth AL, Sandercock P, Spiegelhalter D, et al. Framework for design and evaluation of complex interventions to improve health. BMJ. 2000;321(7262):694-6. Epub 2000/09/15. PubMed PMID: 10987780; PubMed Central PMCID: PMC1118564. 
679

680

681

682 Supporting information

683 Supplementary Text S1. CREDICI II criteria

684 Supplementary Text S2. Details of measurement of measures

685 Table S1. Socio-demographic, lifestyle and health characteristics by intervention and control

686 group of each city among persons in the UHCE study at baseline ( $N=1844)$.

687 Table S2. Lifestyle and health outcomes by intervention and control group of each city among 688 persons in the UHCE study at follow-up $(\mathrm{N}=1844)$.

689 Table S3. Effect of the UHCE approach on outcomes for each city separately.

690 Table S4. Effect of each UHCE care-pathway on outcomes for at-risk persons in the intervention

691 group who enrolled in a specific care-pathway compared to at-risk persons in the control group.

692 Table S5. Mean social and health care use in past 12 months at follow-up and effects of the

693 UHCE approach with the control group as reference $(\mathrm{N}=1844)$. 